\title{
Three new species of Grosphus Simon 1880, (Scorpiones: Buthidae) from Madagascar; possible vicariant cases within the Grosphus bistriatus group of species
}

\author{
Wilson R. Lourenço', Lucienne Wilméll
}

\author{
Correspondence: \\ Wilson R. Lourenço \\ Muséum national d'Histoire naturelle, Sorbonne Universités, \\ Institut de Systématique, Evolution, Biodiversité (ISYEB), \\ UMR7205-CNRS, MNHN, UPMC, EPHE, CP 53, 57 rue Cuvier, 75005 \\ Paris, France \\ Email: arachne@mnhn.fr
}

\begin{abstract}
A revised redescription is proposed for Grosphus bistriatus Kraepelin 1900. Three new species, associated with both G. bistriatus and G. ankarafantsika Lourenço 2003 are described. Some comments on biogeographic aspects linking the new species with both $G$. bistriatus and $G$. ankarafantsika are also provided.
\end{abstract}

\section{RÉSUMÉ}

Une nouvelle description révisée est proposée pour Grosphus bistriatus Kraepelin 1900. Trois nouvelles espèces associées à $G$. bistriatus et G. ankarafantsika Lourenço 2003 sont décrites. Des remarques sur les aspects biogéographiques portant sur les nouvelles espèces ainsi que sur $G$. bistriatus et $G$. ankarafantsika sont également formulées.

\section{INTRODUCTION}

As already outlined in recent papers, a considerable number of new species have been added to the genus Grosphus Simon, in recent years (Lourenço \& Wilmé 2015a,b). Among these various cases, some of the recently described species showed some clear associations with other members of this genus sometimes described more than 100 years ago. It is well established that the taxonomy of Grosphus, one of the several endemic genera in Madagascar, is notably complicated, particularly aspects of species' delimitations. For a more detailed discussion about the characters used in the taxonomy of Grosphus, see Lourenço (2014), Lourenço and Wilmé $(2015 a, b)$ and Lourenço et al. $(2007,2009)$.

In an attempt to stabilize the taxonomic positions of Grosphus bistriatus and G. limbatus (Pocock 1889), Lourenço (2003), proposed a redescription of these two species. Prior to this publication, both species had been reported from numerous sites on the island; many of these records certainly being misidentifications (Lourenço 1996). The taxonomic status of $G$. limbatus was finally clarified in a recent publication (Lourenço and Wilmé 2015a). For taxonomic details refer also to Lourenço (2003).

For quite a long period, the precise identity of Grosphus bistriatus appeared somewhat confused. This species was described by Kraepelin (1900) on the basis of two specimens (syntypes) collected near Tulear in the South of Madagascar. Fage (1929) proposed a redescription based on several specimens from different localities including some from the 'Massif d'Ambre' and 'Maevatanana' in the North range of the island. One of the syntypes, deposited in Paris and preserved in alcohol, was probably already faded when Fage examined it. For instance, the coloration described by Fage was based on the other specimens. The morphology of the basal middle lamellae of the female pectines, illustrated by Fage (1929), also differs from that of the syntype. In his diagnosis of G. bistriatus, Lourenço (1996) accepted the redescription proposed by Fage (1929) and indicated the presence of the species in the 'Réserve naturelle intégrale $n^{\circ} 7$, de l'Ankarafantsika); a misidentification once again confirmed by Lourenço (2001).

The subsequent study of freshly collected material of Grosphus bistriatus from the 'type locality' (region of Tulear), brought clarification as to the coloration and patterns of pigmentation of the species. In addition, the precise morphology of the basal middle lamellae of female pectines was confirmed and described (Lourenço 2003). Finally, the population distributed in the Ankarafantsika Reserve was confirmed as being a different new species, described as G. ankarafantsika Lourenço 2003.

In the present note, we comment and confirm once more the status of Grosphus bistriatus, and a new redescription is proposed based on further material collected in the region of Tuléar. Three 


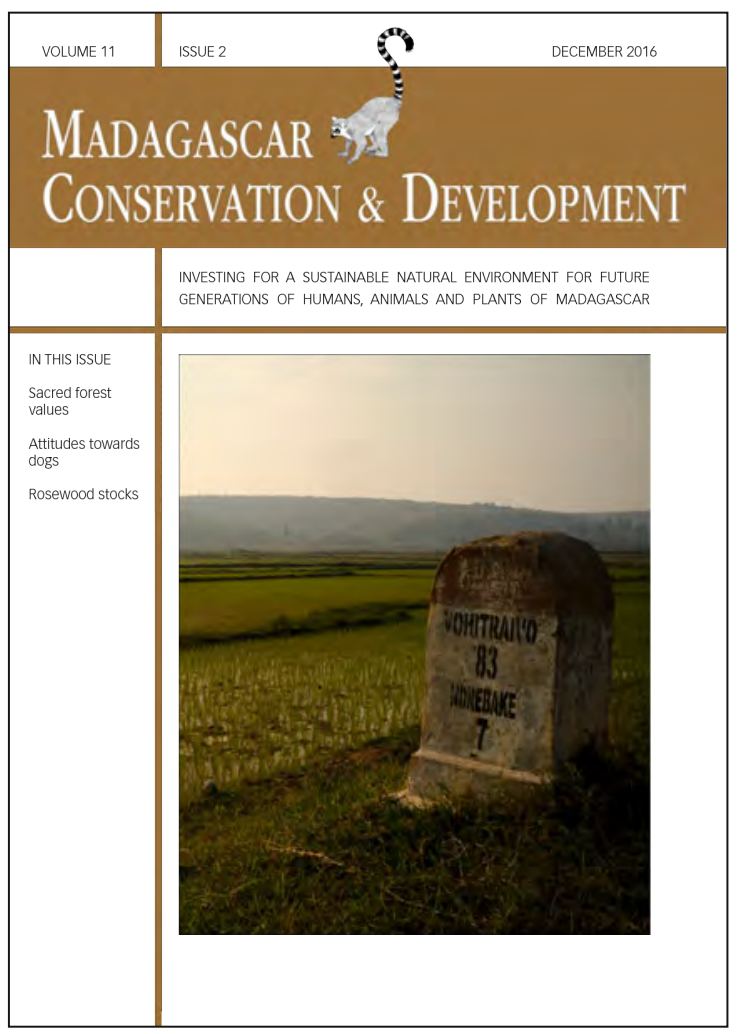

Madagascar Conservation \& Development is the journal of Indian Ocean e-Ink. It is produced under the responsibility of this institution. The views expressed in contributions to MCD are solely those of the authors and not those of the journal editors or the publisher.

All the Issues and articles are freely available at http://www.journalmcd.com

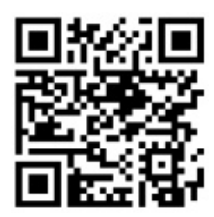

Contact Journal MCD

info@journalmcd.net for general inquiries regarding MCD funding@journalmcd.net to support the journal

Madagascar Conservation \& Development Institute and Museum of Anthropology

University of Zurich

Winterthurerstrasse 190

$\mathrm{CH}-8057$ Zurich

Switzerland

Indian Ocean e-Ink

Promoting African Publishing and Education

www.ioeink.com

Missouri Botanical Garden (MBG)

Madagascar Research and Conservation Program BP 3391

Antananarivo, 101, Madagascar 
other new species are also described, associated both with $G$. bistriatus and G. ankarafantsika. some biogeographic comments are also added, in attempt to explain these new cases of disrupted distribution among elements of the previously defined Grosphus groups.

\section{MATERIAL AND METHODS}

Material related to Grosphus bistriatus, Grosphus ankarafantsika and the new species are now deposited in Muséum national d'Histoire naturelle, Paris. Illustrations and measurements were produced using a Wild M5 stereomicroscope with a drawing tube and an ocular micrometer. Measurements follow Stahnke (1970) and are given in mm. Trichobothrial notations follow Vachon (1974) and morphological terminology is after Vachon (1952) and Hjelle (1990).

\section{TAXONOMIC TREATMENT}

Family Buthidae C. L. Koch 1837

Genus Grosphus Simon 1880

\section{REDESCRIPTION OF Grosphus bistriatus Kraepelin 1900 (FIGURES 1-4).}

\author{
Grosphus bristriatus Kraepelin 1900: 14. \\ Grosphus bistriatus: Kraepelin 1901: 267. \\ Grosphus bistriatus var. pallicauda Strand 1908: 485. \\ Grosphus bistriatus: Fage 1929: 651. \\ Grosphus bistriatus: Lourenço 1996: 13. \\ Grosphus bistriatus: Lourenço 2003:143.
}

Redescription based on a two males and one female collected in the region $\mathrm{N}$ of Tuléar, Ifaty, in dry spiny-bush forest, under leaves, IX/2001 (W. Lourenço)

Morphometric measurements together with those of the new species. Coloration. Basically yellowish. Prosoma: carapace pale yellow with two longitudinal blackish lines behind the median eyes; one small dark spot on the anterior margin and two on the posterior margin which fuses with the longitudinal blackish bands present over the tergites; eyes surrounded by black pigment. Mesosoma: yellowish with two longitudinal blackish bands over tergites I-VI, more densely marked on the posterior half of each. Metasoma: all segments yellow, with some dark pigmentation over the ventral aspect, more dense on the fifth; two diffuse spots present on the dorsal face of segment $V$. Vesicle yellow with dispersed light brownish spots laterally and ventrally; aculeus reddish-yellow. Venter: coxapophysis, sternum, genital operculum and pectines yellowish; sternites yellow. Chelicerae yellowish, without any variegated pigmentation; only a few dark spots at the base of fingers; fingers reddish. Pedipalps: yellowish globally without any pigmentation. Legs yellowish with discrete brownish variegated pigmentation.

Morphology. Carapace intensely granular; anterior margin almost straight with a weak median concavity. All carinae weak to moderate; furrows moderate. Median ocular tubercle anterior to the center of carapace; median eyes separated by a little more than one ocular diameter. Three pairs of lateral eyes. Sternum between sub-triangular and sub-pentagonal. Mesosoma: tergites with a thin and intense granulation. Median carina moderate in all ter- gites. Tergite VII pentacarinate. Venter: genital operculum consisting of two subtriangular plates. Pectines: pectinal tooth count 27-30 for males and 24-25 for female; basal middle lamellae of each pecten not dilated in males; elongated and curved in females, widening on proximal half. Sternites smooth with moderately elongated stigmata; VII with four vestigial carinae and a few thin granules. Metasoma: segments I and II with 10 carinae, moderately crenulate. Segments III and IV with 8 carinae, moderately crenulate. Segment $\mathrm{V}$ with 5 carinae, the dorsal carinae being only weakly marked. Dorsal carinae on segments I-IV without any posterior spinoid granules. Intercarinal spaces moderately granular. Telson with very few granules on lateral and ventral surfaces; dorsal surface smooth; aculeus moderately curved and shorter than the vesicle; subaculear tooth absent. Cheliceral dentition characteristic of the family Buthidae (Vachon 1963); two distinct basal teeth present on the movable finger, the more basal one being slightly reduced; ventral aspect of both finger and manus with dense, long setae. Pedipalps: femur pentacarinate; Patella with carinae represented by some spinoid granules, only on the internal face; Tibia smooth without carinae, all faces weakly granular to smooth. Fixed and movable fingers with 10/11 oblique rows of granules. Trichobothriotaxy; orthobothriotaxy A- $\alpha$ (Vachon 1974, 1975). Legs: tarsus with numerous short thin setae ventrally. Patellar spurs present on legs III and IV, pedal spurs present on legs I to IV; all spurs strong.

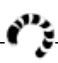

Grosphus eliseanneae sp. n. (Figures 5, 6, 9-15).

Type material. Female holotype. Madagascar, ex-Province d'Antsiranana (Diego-Suarez), Région DIANA. Ambilobe Beramanja, dry bush vegetation, under log (death wood), X/1969 (J.-M. Betsch). Holotype deposited in the Muséum national d'Histoire naturelle, Paris.

Patronym: The specific name honors Elise-Anne Leguin (MNHN) for her continuous contribution to the study of scorpions.

Diagnosis: A scorpion of medium to small size in relation to other species within the genus; female holotype with a total length of $46.6 \mathrm{~mm}$. General coloration yellow to pale yellow with conspicuous dark longitudinal zones on carapace and tergites. Anterior margin of carapace strongly granular. Pectines with 24-24 teeth; basal middle lamellae of each pecten strongly dilated in female, but moderately elongated and covering only the first tooth; constantly narrowing from the base to the apex (diagnostic). Metasomal segments I and II with 10 carinae; III and IV with 8 carinae. Fixed and movable fingers of pedipalps with 11-12 oblique rows of granules respectively. Trichobothriotaxy, orthobothriotaxy, type A- $\alpha$.

Relationships: The general morphology and pigmentation pattern of the new species shows it to be close to the Grosphus limbatus / G. bistriatus group. This group of species is largely distributed in the south-western and central regions of Madagascar. The closest related species however, is $G$. ankarafantsika Lourenço 2003 (Figures 7, 8), described from the Ankarafantsika reserve (see biogeographic section). Both species can be readily 


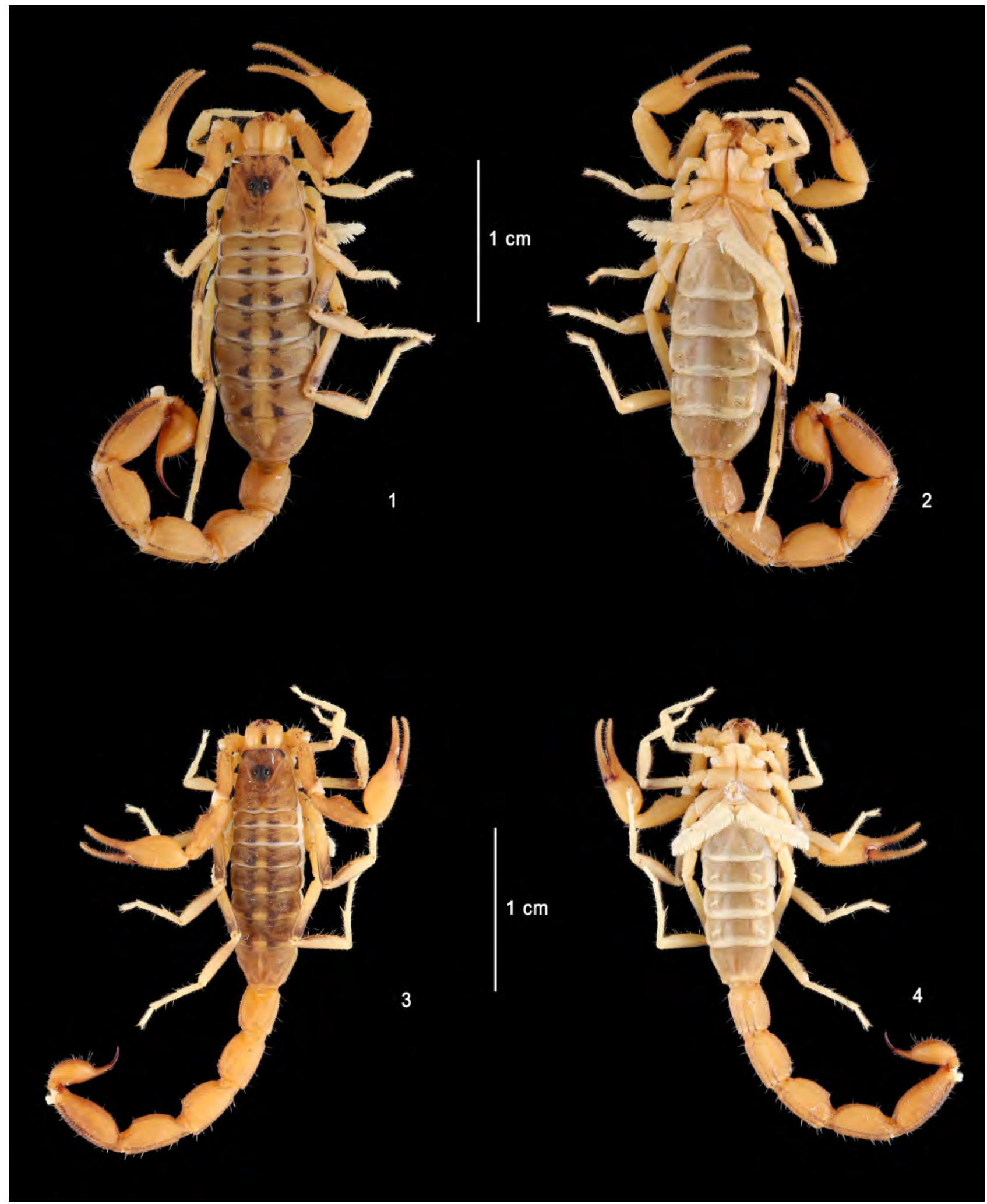

Figures 1-4. Grosphus bistriatus. Female and male topotypes. Habitus, dorsal and ventral aspects. 

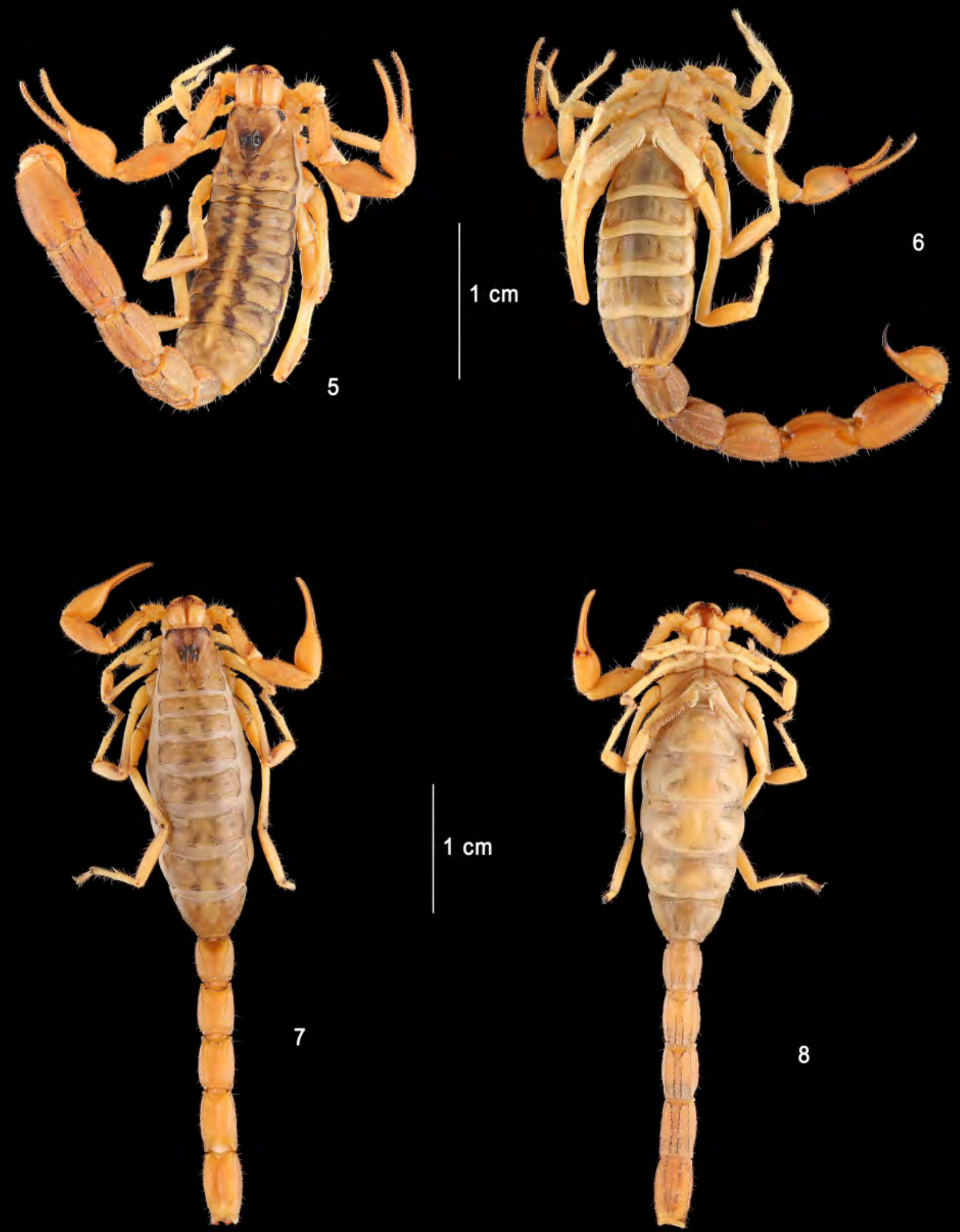

$1 \mathrm{~cm}$

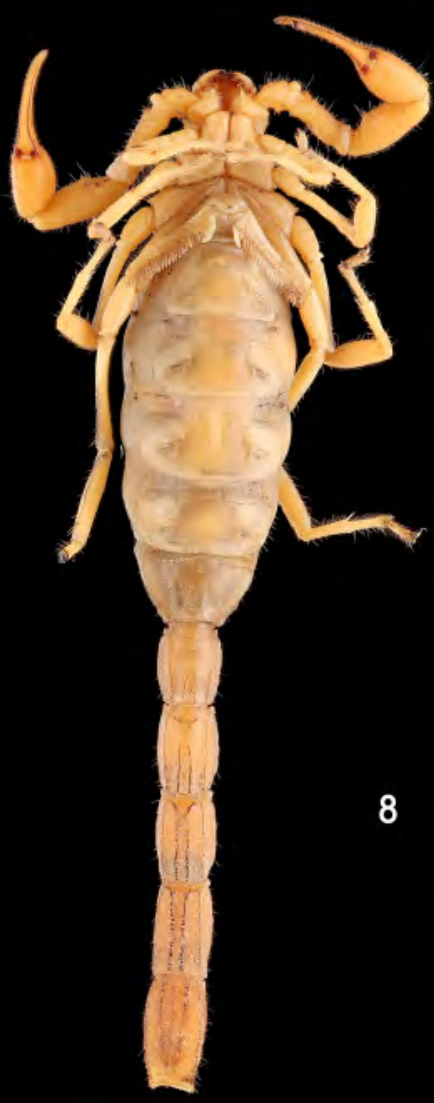

Figures 5, 6. Grosphus eliseanneae sp. n. Female holotype. Habitus, dorsal and ventral aspects 


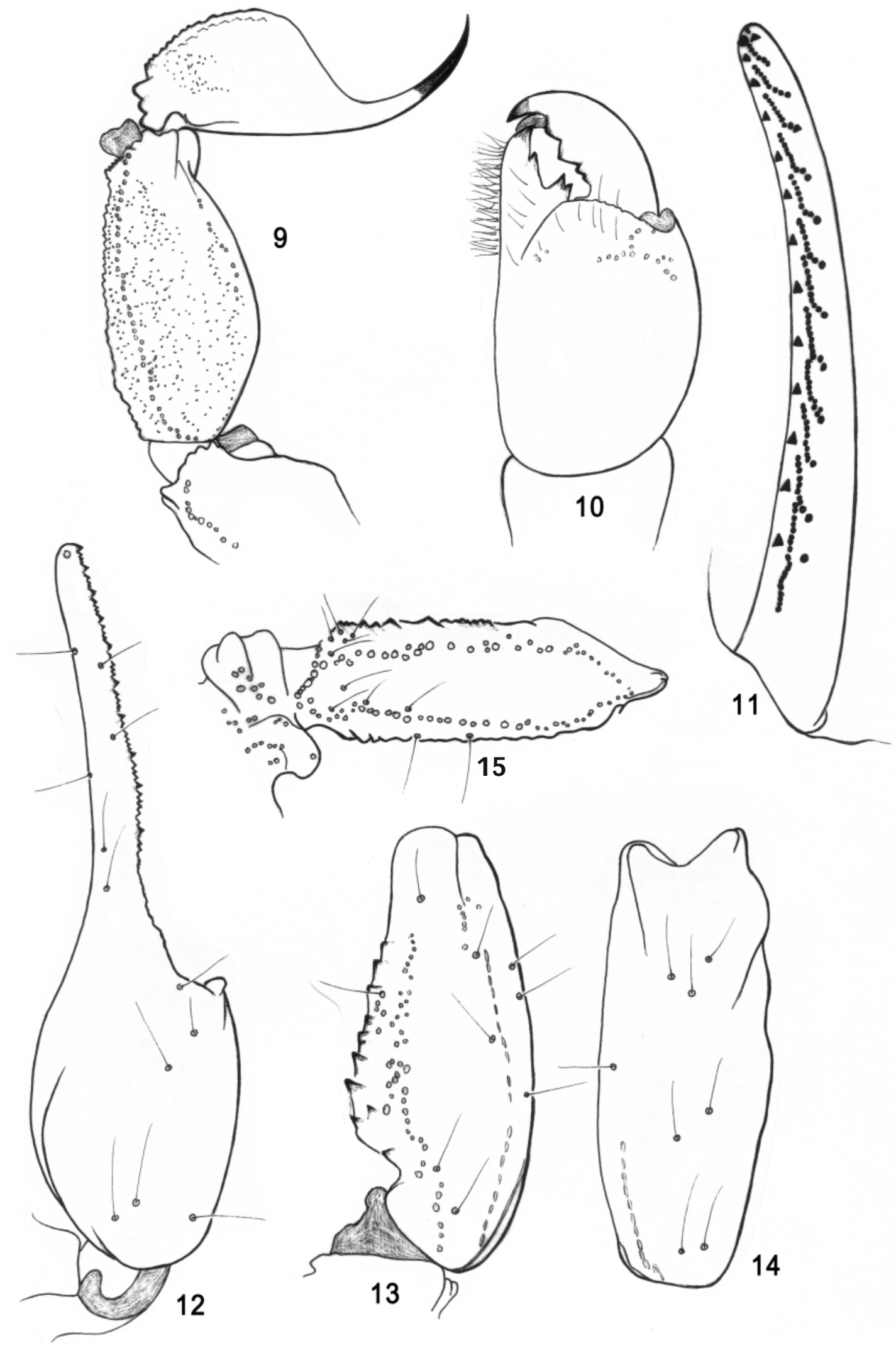

Figures 9-15. Grosphus eliseanneae sp. n. Female holotype. Figure 9. Metasomal segment $\mathrm{V}$ and telson, lateral aspect. Figure 10. Chelicera, dorsal aspect.

Figure 11. Cutting edge of movable finger.

Figures 12-15. Trichobothrial pattern. 12. Chela, dorso-external aspect.

Figures 13, 14. Patella, dorsal and external aspects.

Figure 15. Femur, dorsal aspect. 
distinguished by the following characters: (i) pigmentation and spots better marked in the new species, (ii) better marked carinae and granulations on the new species, (iii) basal middle lamellae of pectines less elongate in the new species, covering only the first tooth, whereas in G. ankarafantiska the basal lamellae covers 2-3 teeth. Moreover, both species present a totally allopatric distribution.

Description based on female holotype (male unknown). Morphometric values following the description. Coloration. Overall yellow to pale yellow with dark zones on the body and appendages. Prosoma: carapace yellow with an anterior dark brown zone, forming approximately an inverted triangle; lateral edges dark brown; eyes surrounded by black pigment. Mesosoma yellowish, with lateral edges of tergites dark brown. Metasomal segments I to III yellow; IV and V slightly reddish to reddish-yellow; some diffuse pigmentation on the carinae. Telson reddish-yellow without spots; aculeus reddish-yellow at the base and dark reddish on the tip. Venter: coxapophysis, sternum, genital operculum pectines and sternites pale yellow; sternites slightly darker. Chelicerae yellow with some variegated pigmentation; fingers yellow with reddish teeth. Pedipalps yellow with infuscated carinae; rows of granules on chela fingers reddish. Legs pale yellow with slightly infuscated zones.

Morphology. Carapace weakly to moderately granular except on the anterior triangular zone which is more strongly granular; anterior margin with a weak median concavity. All carinae weak; furrows moderately developed. Median ocular tubercle anterior to the centre of the carapace; median eyes separated by approximately one ocular diameter. Three pairs of lateral eyes. Sternum subtriangular in shape. Mesosomal tergites with a moderately marked granulation. Median carina moderately marked in all tergites. Tergite VII pentacarinate. Venter: genital operculum consisting of two suboval plates. Pectines: pectinal teeth count 24-24; basal middle lamellae of each pecten strongly dilated, but moderately elongated, covering only the first proximal tooth; narrowing from the base to the apex. Sternites smooth, with elongated stigmata; VII with weakly marked carinae. Metasomal segments I and II with 10 carinae, moderately crenulate. Segments III and IV with 8 carinae, moderately crenulate. Segment $\mathrm{V}$ with 5 carinae. Dorsal carinae on segments II to IV without posterior spinoid granules. Intercarinal spaces moderately to strongly granular. Telson with a moderate to weak granulation over latero-ventral and ventral surfaces; its dorsal surface smooth; aculeus weakly curved and slightly shorter than the vesicle; subaculear tooth absent. Cheliceral dentition characteristic of the family Buthidae (Vachon 1963); two distinct basal teeth present on the movable finger; ventral aspect of both fingers and of manus with dense, long setae. Pedipalps: femur pentacarinate with moderate spinoid carinae; patella with dorsointernal and dorsoexternal carinae and with some spinoid granules on the internal face; chela without carinae and with the internal face smooth. Fixed and movable fingers with 11-12 oblique rows of granules respectively. Trichobothriotaxy; orthobothriotaxy A- $\alpha$ (Vachon 1974, 1975). Legs: tarsus with numerous short thin setae ventrally, forming a brush. Tibial spurs present on legs III and IV, thin and long; pedal spurs present on legs I to IV, moderate to strong.

Morphometric values (in $\mathrm{mm}$ ) of the female holotype. Total length (including telson), 46.6. Carapace: length, 5.2; anterior width, 3.9; posterior width, 6.1. Mesosoma length, 13.1. Metaso- mal segments. I: length, 3.5; width, 3.5; II: length, 3.8; width, 3.2; III: length, 4.0; width, 3.2; IV: length, 4.8; width, 3.2; V: length, 6.1; width, 3.1; depth, 2.8. Telson length, 6.1. Vesicle: width, 2.5; depth, 2.3. Pedipalp: femur length, 4.3 , width, 1.4 ; patella length, 5.2, width, 2.2; chela length, 8.3, width, 2.1, depth, 2.2; movable finger length, 5.2

\section{(") \\ Grosphus waeberi sp. n. (Figures 16-25).}

Type material. Male holotype and male paratype. Madagascar, ex-Province of Mahajanga, Région Sofia, near Maromandia village, IX/2001 (Local people to W. Lourenço). Holotype and paratype deposited in the Muséum national d'Histoire naturelle, Paris.

Patronym: The specific name honors Patrick O. Waeber (ETH Zurich and MWC Madagascar) for his research and dedication to the conservation of some of the most threatened species of the Madagascar biodiversity.

Diagnosis: A scorpion of small size in relation to other species within the genus; male holotype with a total length of $36.5 \mathrm{~mm}$. General coloration yellow to pale yellow with two inconspicuous light brown longitudinal stripes over carapace and tergites. Anterior margin of carapace with a few granules; other zones with a thin granulation. Pectines with 26-27 teeth; (holotype) and 30-29 teeth (paratype); basal middle lamellae of each pecten not dilated in males. Metasomal segments I to III with 10 carinae; IV with 8 carinae; intermediate carinae incomplete on III. Femur and patella of pedipalps with some spinoid carinae, moderately marked. Fixed and movable fingers of pedipalps with 11-12 oblique rows of granules respectively. Trichobothriotaxy, orthobothriotaxy, type A- $\alpha$.

Relationships: The general morphology and pigmentation pattern of the new species shows it to be close to the Grosphus limbatus / G. bistriatus group. This group of species is largely distributed in the South-western and central regions of Madagascar. The closest related species however, is G. bistriatus Kraepelin 1900, described from the region of the Tulear (see biogeographic section). Both species can be readily distinguished by the following characters: (i) pigmentation, granulations and carinae much less marked on the new species, (ii) cutting edges of pedipalp fingers with 11-12 rows of granules in the new species vs. 10-11 in G. bistriatus, (iii) scopula between chela fingers less marked in the new species, (iv) body and appendages slender in the new species - see morphometric values.

Description based on male holotype and male paratype. Morphometric values following the description. Coloration. Overall yellow to pale yellow with a few dark zones on the body and appendages. Prosoma: carapace yellow with an anterior pale reddish-orange zone, approximately forming an inverted triangle; eyes surrounded by black pigment. Mesosoma yellow, with two inconspicuous longitudinal pale brown stripes. Metasoma: segments I to IV yellowish; $V$ slightly reddish-yellow; some pigmentation on the carinae, better marked on IV-V. Telson reddish-yellow without spots; aculeus reddish, darker on the tip. Venter: coxapo- 


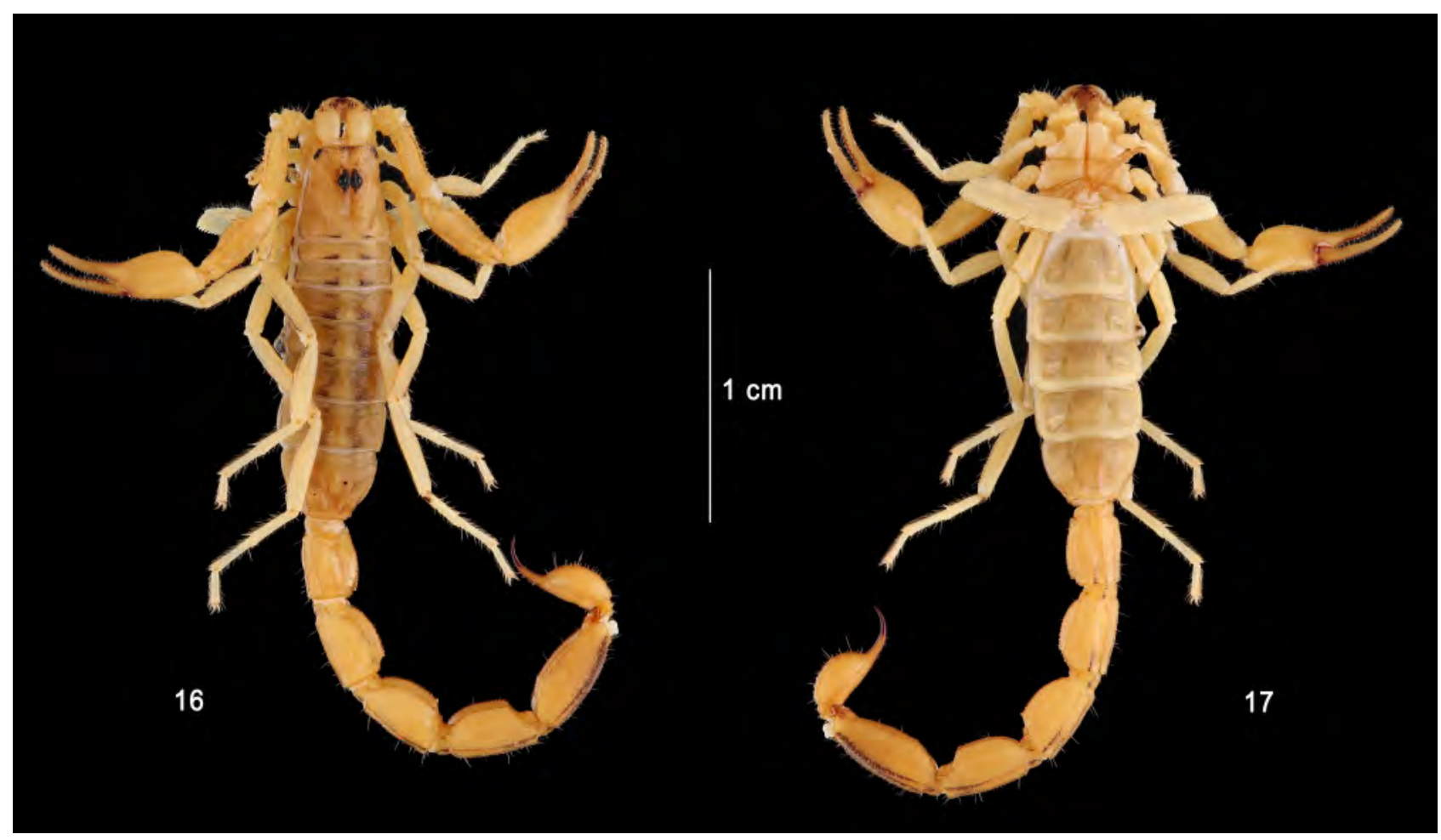

Figures 16, 17. Grosphus waeberi sp. n. Male holotype. Habitus, dorsal and ventral aspects.

physis, sternum, genital operculum pectines and sternites pale yellow. Chelicerae yellow slightly pigmented at the base of fingers; teeth reddish. Pedipalps yellowish with rows of granules on chela fingers reddish. Legs pale yellow; carinae with slightly brownish zones.

Morphology. Carapace weakly granular except on the anterior triangular zone which is moderately granular; anterior margin with a very weak median concavity, almost straight. All carinae weak to obsolete; furrows moderately developed. Median ocular tubercle anterior to the centre of the carapace; median eyes separated by one ocular diameter. Three pairs of lateral eyes. Sternum sub-triangular in shape. Mesosomal tergites with a very weak granulation. Median carina moderately to weakly marked in all tergites. Tergite VII pentacarinate. Venter: genital operculum consisting of two suboval plates. Pectines: pectinal teeth count 26-27 (holotype), 30-29 (paratype); basal middle lamellae of each pecten not dilated. Sternites smooth, lustrous with elongated stigmata; VII with vestigial carinae and a few granulations. Metasomal segments I to III with 10 carinae, moderately crenulate. Segment IV with 8 carinae, moderately crenulate. Segment $\mathrm{V}$ with 5 carinae. Dorsal carinae on segments II to IV without posterior spinoid granules. Intercarinal spaces moderately to weakly granular. Telson with a weak granulation over latero-ventral and ventral surfaces; its dorsal surface smooth; aculeus weakly curved and slightly shorter than the vesicle; subaculear tooth absent. Cheliceral dentition characteristic of the family Buthidae (Vachon 1963); two distinct basal teeth present on the movable finger; ventral aspect of both fingers and of manus with dense, long setae. Pedipalps: femur pentacarinate with moderate spinoid carinae; patella with dorsointernal and dorsoexternal carinae and with a few spinoid granules on the internal face; chela without carinae and with the internal face smooth. Fixed and movable fingers with 11-12 oblique rows of granules respectively. Trichobothriotaxy; orthobothriotaxy A- $\alpha$ (Vachon 1974, 1975). Legs: tarsus with numerous short thin setae ventrally. Tibial spurs present on legs III and IV, thin and long; pedal spurs present on legs I to IV, moderate to strong.

Female unknown.

Morphometric values (in $\mathrm{mm}$ ) of the male holotype of Grosphus waeberi sp. n. and a male topotype of $G$. bistriatus. Total length (including telson), 36.5/35.1. Carapace: length, 3.7/3.6; anterior width, 2.7/2.8; posterior width, 3.9/4.2. Mesosoma length, 10.3/9.9. Metasomal segments. I: length, 2.8/2.7; width, 2.3/2.5; II: length, 3.2/3.1; width, 2.2/2.4; III: length, 3.3/3.2; width, 2.2/2.3; IV: length, 3.7/3.6; width, 2.1/2.3; V: length, 4.8/4.5; width, 2.1/2.4; depth, 2.1/2.3. Telson length, 4.7/4.5. Vesicle: width, 1.6/1.8; depth, 1.6/1.8. Pedipalp: femur length, 3.3/3.4, width, 1.1/1.3; patella length, 4.0/4.1, width, 1.4/1.7; chela length, 6.5/6.7, width, 1.8/2.0, depth, 1.8/2.0; movable finger length, 3.7/3.8

\section{(")}

Grosphus sabineae sp. n. (Figures 26-35).

Type material. Female holotype. Madagascar, ex-Province de Toliara, Région Androy, Cap Sainte-Marie, VI/1967 (J.-M. Betsch). Holotype deposited in the Muséum national d'Histoire naturelle, Paris.

Patronym: The specific name honors Dr Sabine Jourdan (Paris) for her constant support to the senior author in his researches.

Diagnosis: A scorpion of medium to large size in relation to other species within the genus; female holotype with a total length of $55.7 \mathrm{~mm}$. General coloration yellow to pale yellow with very inconspicuous spots on body and appendages. Anterior margin of carapace emarginated and moderately granular. Pectines with 25-25 teeth; basal middle lamellae of each pecten strongly 


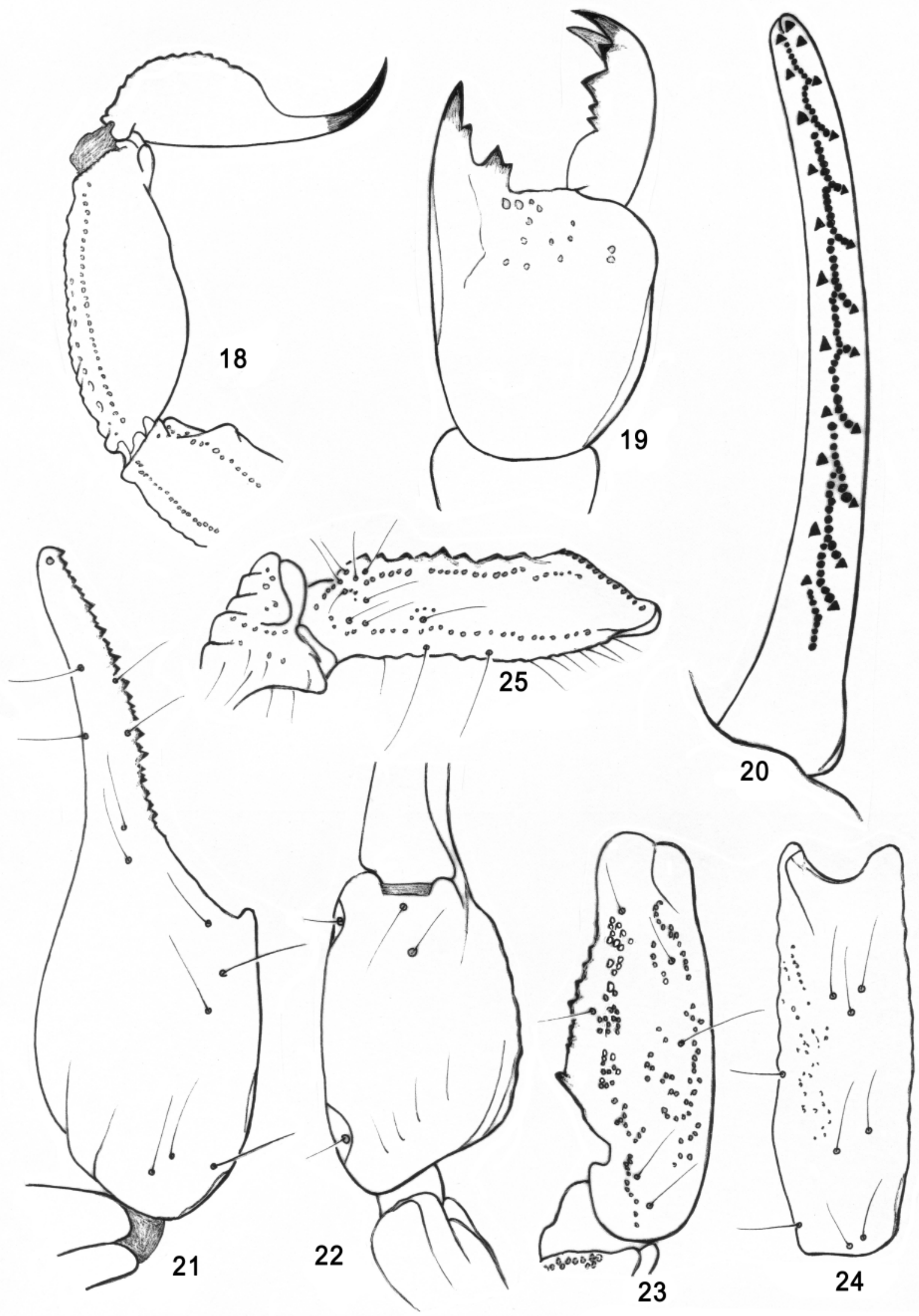

Figures 18-25. Grosphus waeberi sp. n. Male holotype.

Figure 18. Metasomal segment $\mathrm{V}$ and telson, lateral aspect. Figure 19. Chelicera, dorsal aspect. Figure 20. Cutting edge of movable finger.

Figures 21-25. Trichobothrial pattern. Figures 21, 22. Chela, dorso-external and ventral aspects. Figures 23, 24. Patella, dorsal and external aspects. Figure 25. Femur, dorsal aspect. 
dilated in female, moderately elongated and covering only the first proximal tooth. Metasomal segments I and II with 10 carinae; III and IV with 8 carinae. Femur and patella of pedipalps with moderately to weakly spinoid carinae. Fixed and movable fingers of pedipalps with 11-12 oblique rows of granules respectively. Trichobothriotaxy, orthobothriotaxy, type A- $\alpha$.

Relationships: The general morphology and pigmentation pattern of the new species shows it to be close to the Grosphus limbatus/G. bistriatus group. This group of species is largely distributed in the South-western and central regions of Madagascar. The closest related species however, remains Grosphus bistriatus Kraepelin 1900 described from the region of Tulear (see biogeographic section). Both species can be readily distinguished by the following characters: (i) the new species shows a global larger size, with distinct morphometric values (ii) a much paler coloration in the new species with only inconspicuous spots on body and appendages (iii) carinae and granulations are less marked in the new species (iv) anterior margin of carapace is emarginated in the new species but straight in G. bistriatus.

Description based on female holotype. Morphometric values

following the description. Coloration. Overall yellow to pale yellow without any conspicuous spots on the body and appendages. Prosoma: carapace yellow with only the eyes surrounded by black pigment. Mesosoma yellow, with inconspicuous pale brown zones on the posterior edges of tergites. Metasomal segments I to $\mathrm{V}$ yellowish with some blackish zones on the carinae, better markes on segments IV-V. Telson pale yellow without spots; aculeus reddish, darker on tip. Venter: coxapophysis, sternum, genital operculum pectines and sternites yellow to pale yellow. Chelicerae yellow without any variegated pigmentation; fingers with reddish teeth. Pedipalps yellow with rows of granules on chela fingers reddish. Legs pale yellow with some infuscations on carinae.

Morphology. Carapace weakly to moderately granular; anterior margin with a moderate emargination. All carinae weak; furrows moderately developed. Median ocular tubercle anterior to the centre of the carapace; median eyes separated by a little more than one ocular diameter. Three pairs of lateral eyes. Sternum sub-triangular in shape. Mesosomal tergites with thin granulations. Median carina moderately to weakly marked in all tergites. Tergite VII pentacarinate. Venter: genital operculum consisting of two subtriangular plates. Pectines: pectinal teeth count 25-25; basal middle lamellae of each pecten strongly dilated but moderately elongated and covering only the most proximal tooth. Sternites smooth, with elongated stigmata; VII with vestigial carinae. Metasoma: segments I and II with 10 carinae, moderately crenulate. Segments III and IV with 8 carinae, moderately crenulate. Segment $\checkmark$ with 5 carinae. Dorsal carinae on segments II to IV without posterior spinoid granules. Intercarinal spaces moderately to weakly granular. Telson with a moderate to weak granulation over

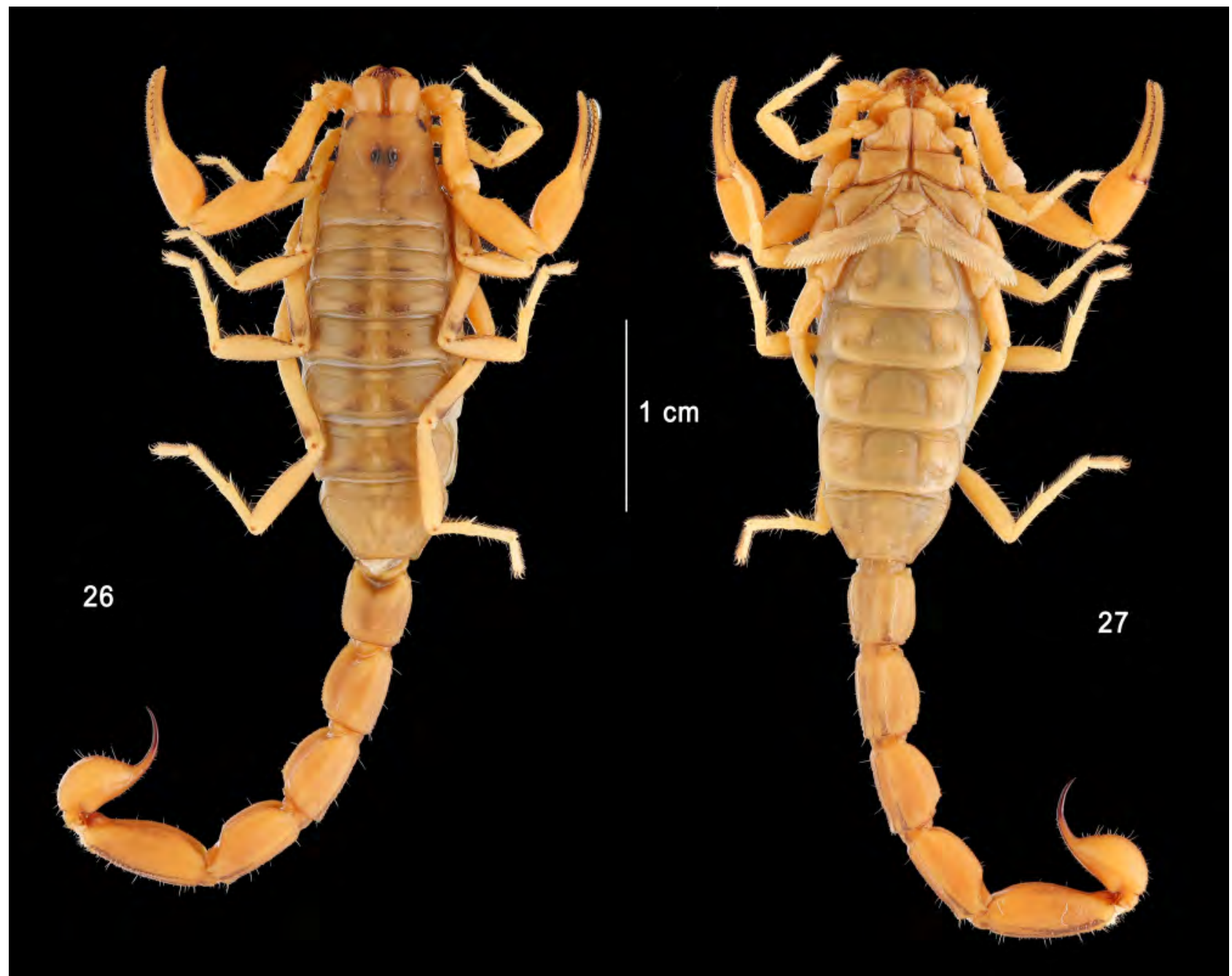

Figures 26-27. Grosphus sabineae sp. n. Female holotype. Habitus, dorsal and ventral aspects. 


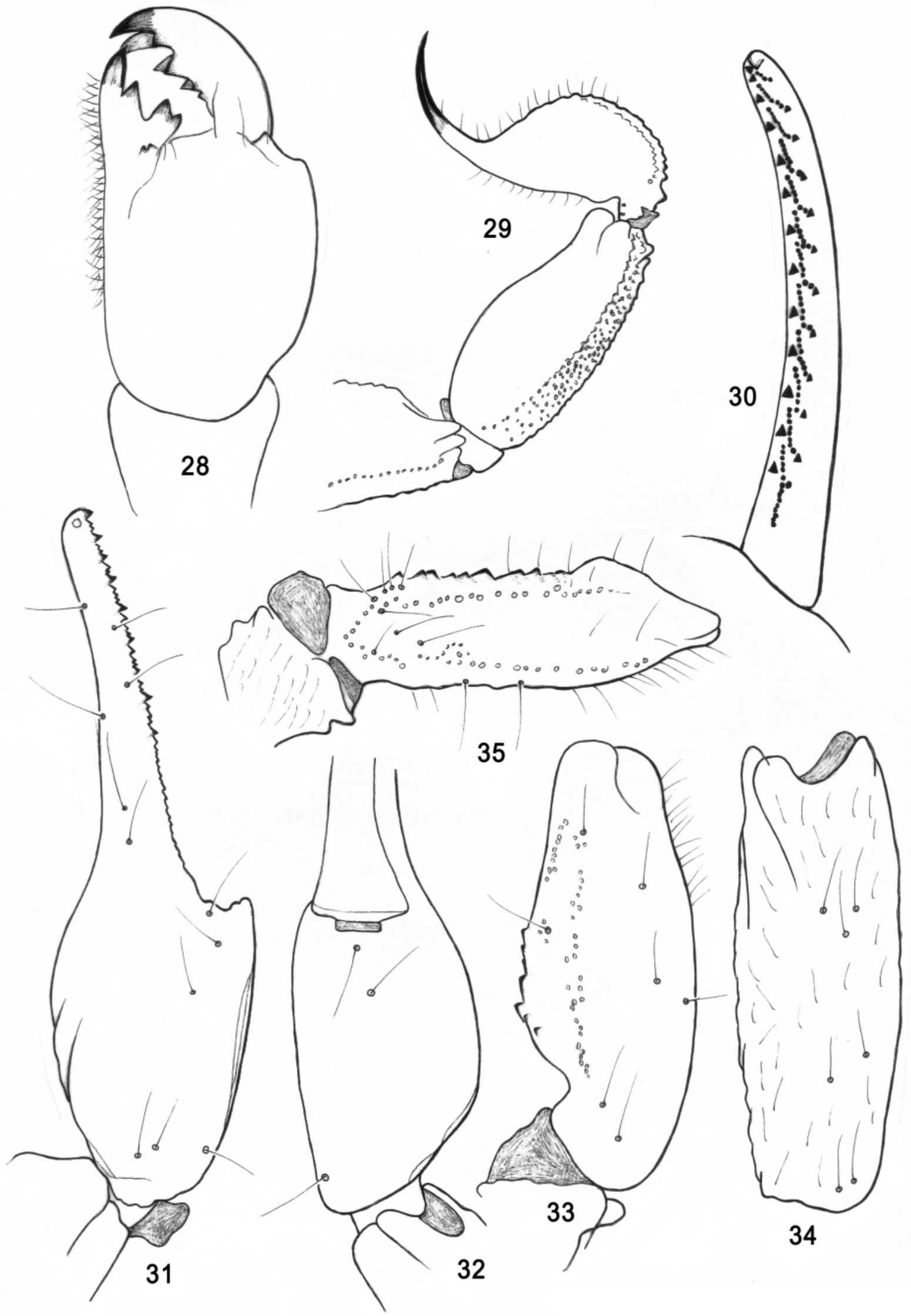

Figures 28-35. Grosphus sabineae sp. n. Female holotype.

Figure 29. Metasomal segment $\mathrm{V}$ and telson, lateral aspect.

Figure 30. Cutting edge of movable finger.

Figures 31-35. Trichobothrial pattern. Figures 31, 32. Chela, dorso-external and ventral aspects. Figures 33, 34. Patella, dorsal and external aspects. Figure 35. Femur, dorsal aspect. 
latero-ventral and ventral surfaces; its dorsal surface smooth; aculeus moderately curved and slightly shorter than the vesicle; subaculear tooth absent. Cheliceral dentition characteristic of the family Buthidae (Vachon 1963); two distinct basal teeth present on the movable finger; ventral aspect of both fingers and of manus with dense, long setae. Pedipalps: femur pentacarinate with moderate spinoid carinae; patella with dorsointernal and dorsoexternal carinae and with a few spinoid granules on the internal face; chela without carinae and with the internal face smooth. Fixed and movable fingers with 11-12 oblique rows of granules respectively. Trichobothriotaxy; orthobothriotaxy A- $\alpha$ (Vachon 1974, 1975). Legs: tarsus with numerous short thin setae ventrally. Tibial spurs present on legs III and IV, thin and long; pedal spurs present on legs I to IV, moderate to strong.

Male unknown.

Morphometric values (in $\mathrm{mm}$ ) of the female holotype of Grosphus sabineae sp. n. and for a female topotype of G. bistriatus. Total length (including telson), 55.7/42.9. Carapace: length,
5.7/4.6; anterior width, 4.4/3.7; posterior width, 6.9/5.4. Mesosoma length, 16.8/12/1. Metasomal segments. I: length, 4.1/3.2; width, 3.7/3.0; II: length, 4.6/3.6; width, 3.5/2.8; III: length, 4.9/3.9; width, 3.5/2.8; IV: length, 5.6/4.4; width, 3.5/2.7; V: length, 6.8/5.3; width, 3.5/2.7; depth, 2.9/2.5. Telson length, 7.2/5.8. Vesicle: width, 3.1/2.4; depth, 2.7/2.1. Pedipalp: femur length, 4.8/3.9, width, 1.5/1.2; patella length, 5.7/4.6, width, 2.2/1.8; chela length, 8.9/7.6, width, 2.3/1.8, depth, 2.2/1.7; movable finger length, 5.2/4.6.

\section{BIOGEOGRAPHIC CONSIDERATIONS}

The species belonging to the genus Grosphus are mainly encountered in dry and subarid bioclimates (Cornet 1974) and in two main types of forests, namely the western dry forests and the southwestern dry spiny forest-thickets (Moat and Smith 2007). Four species only occur in humid and subhumid forests; out of the total 27 species recognized nowadays, 23 species (85\%) occur in dry forests and/or dry spiny forest-thickets (Figure 36, Table 1). The second scorpion clade with a high species richness in Mada-

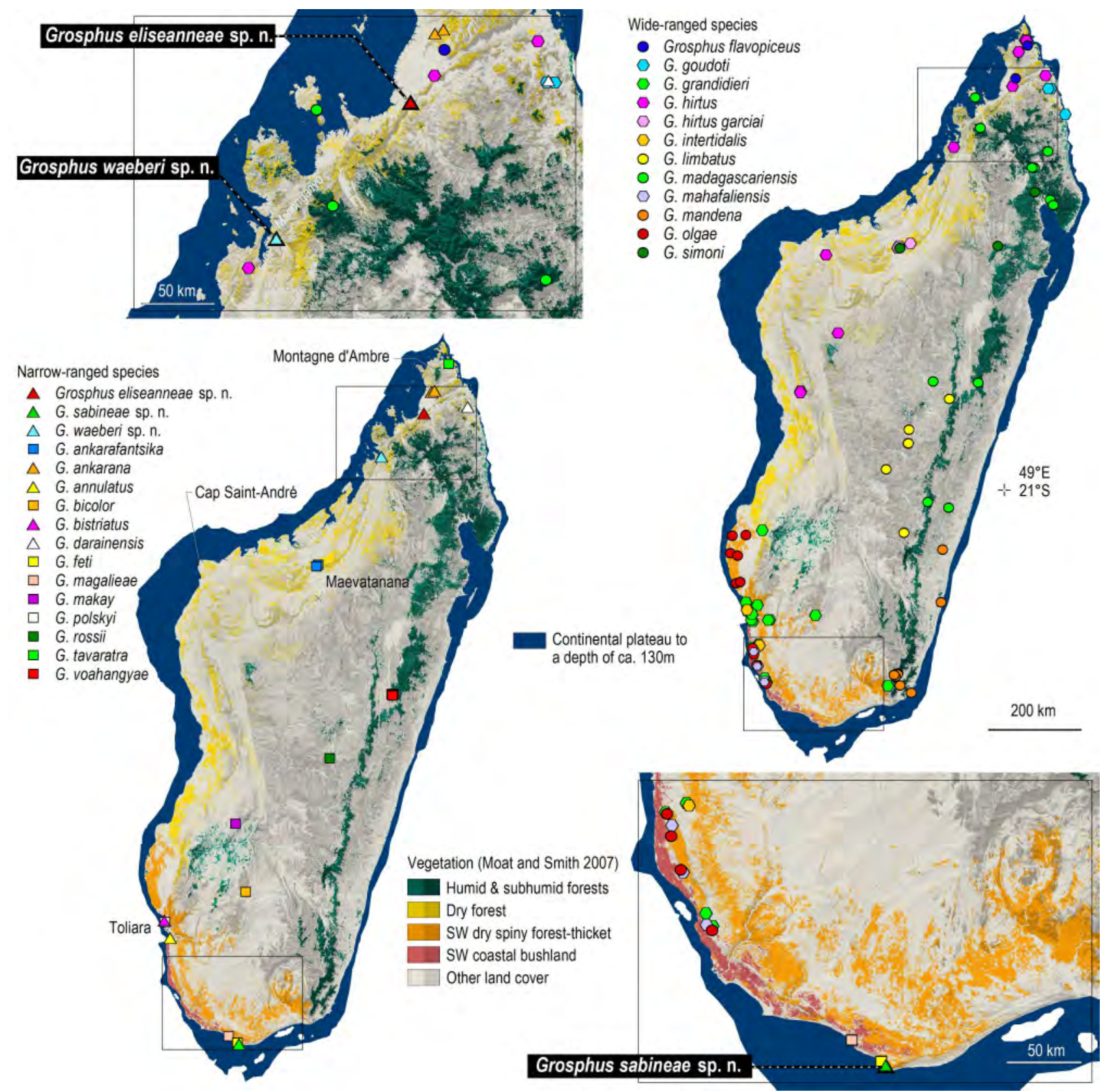

Figure 36. Distribution of the 27 species known in the genus Grosphus according to forest cover. 
Table 1. Scorpion genera endemic to Madagascar with the number of species occurring in the humid and dry biomes, total number of species within each genus, and family, and number of samples available in our database. (fossil taxa are not included; see Wilmé et al. 2012 for Noe4D).

\begin{tabular}{|c|c|c|c|c|}
\hline \multirow{2}{*}{\multicolumn{5}{|c|}{ Buthidae }} \\
\hline & & & & \\
\hline Grosphus & 7 & 23 & 27 & 152 \\
\hline Neogrosphus & 1 & 2 & 3 & 12 \\
\hline Pseudouroplectes & & 5 & 5 & 16 \\
\hline Tityobuthus & 15 & 5 & 19 & 34 \\
\hline Troglotityobuthus & & 1 & 1 & 1 \\
\hline Sub total Buthidae & 23 & 36 & 55 & 215 \\
\hline \multicolumn{5}{|l|}{ Microcharmidae } \\
\hline Neoprotobuthus & 1 & & 1 & 1 \\
\hline 凶icrocharmus & 8 & 6 & 14 & 33 \\
\hline \multicolumn{5}{|l|}{ Sub total } \\
\hline Microcharmidae & 9 & 6 & 15 & 34 \\
\hline \multicolumn{5}{|l|}{ Heteroscorpionidae } \\
\hline 凶eteroscorpion & 3 & 3 & 6 & 8 \\
\hline \multicolumn{5}{|l|}{ Hormuridae } \\
\hline Opisthacanthus & 3 & 7 & 10 & 44 \\
\hline Palaeocheloctonus & & 2 & 2 & 7 \\
\hline Sub total Hormuridae & 3 & 9 & 12 & 51 \\
\hline Totals & 38 & 54 & 88 & 308 \\
\hline
\end{tabular}

gascar is Tityobuthus Pocock 1893, with 19 species described. The majority of the species of Tityobuthus occur in the humid and subhumid, i.e., 15 species out of 19 (79\%) and only 5 species (26\%) are known from dry biomes (Lourenço et al. 2016a, Table 1).

Grosphus eliseanneae sp. n. and G. waeberi sp. n. occur in dry forests of the northwest, and are currently only known from their type locality (Figure 36). They occur in two distinct centers of endemism, respectively in the Ankify and Ampasindava centers of endemism (Wilmé et al. 2006, 2012) bordering the Sambirano belt with its humid and subhumid forests extending towards the west coast in Northern Madagascar. The Sambirano has been shown to act as a dispersal barrier for other clades of scorpions, allowing for speciation on both sides over time (e.g., Lourenço et al. 2015c, 2016b). G. eliseanneae sp. n. and G. waeberi sp. n. seem to be one more case of allopatric speciation in Northern Madagascar from an ancestral population, another typical case complying with the Neogrosphus rule (Lourenço et al. 2015c, 2016b). According to this rule, in a changing environment, a high species richness is linked to a great niche breadth of the ancestor taxon of the group (Lourenço et al. 2015c, 2016b: Table 1). The type localities for these two new species are at distances of 25 to $30 \mathrm{~km}$ from collection localities of the wide-ranged G. hirtus Kraepelin 1901, which is also a dry forest species.

The distance between Grosphus eliseanneae sp. n. and the known localities where G. ankarafantsika has been sampled is at least $400 \mathrm{~km}$, and the distance between the type locality of G. waeberi sp. n. and southwestern Madagascar where G. bistriatus has been recorded (Figure 36 ) is above $1,000 \mathrm{~km}$. Contrary to the humiculous scorpions in the genus Tityobuthus, conducting inventories to document the scorpion fauna in the genus Grosphus does not rely on specialized techniques such as the Winkler traps, and Grosphus spp. are usually sampled by overturning rocks. The 27 species of Grosphus are currently documented with more than 150 samples, while only 34 samples document the 19 species of Tityobuthus in the Noe4D database. Although the documentation of the Grosphus species is far from complete, it is still the best sampled group amongst the endemic scorpions of Madagascar (Table 1, Wilmé et al. 2012). The paucity of inventories to document the range of the Grosphus species is therefore not justified to explain the wide gap of more than 1,000 km between the type locality of $G$. waeberi sp. n. and the distribution in southwestern Madagascar of its closest relative G. bistriatus.

A possible explanation of such disjoint distributions are of two kinds: (i) a passive rafting of an ancestral population by means of wooden debris or a raft of vegetation, similar to the sweepstake model proposed for the colonisation of the mammals of Madagascar (Simpson 1940, Stankiewicz et al. 2006); or (ii) populations of both species have disappeared from the historical range, such as in the case of rising sea level over the continental plateau after periods of low sea level stand, or more recently due to anthropological deforestation.

In the first scenario, a fertile female or a pair belonging to the common ancestral population of Grosphus waeberi sp. n. and G. bistriatus could have been passively transported along the western coast of the island. The type locality of G. waeberi sp. n. lies at a short distance from the bank of the lower portion of the Manongarivo River, near its estuary in the Bay of Sahamalaza, and G. bistriatus is encountered at a short distance from the ocean in the southwest (Figure 36). The mode of reproduction of the scor-

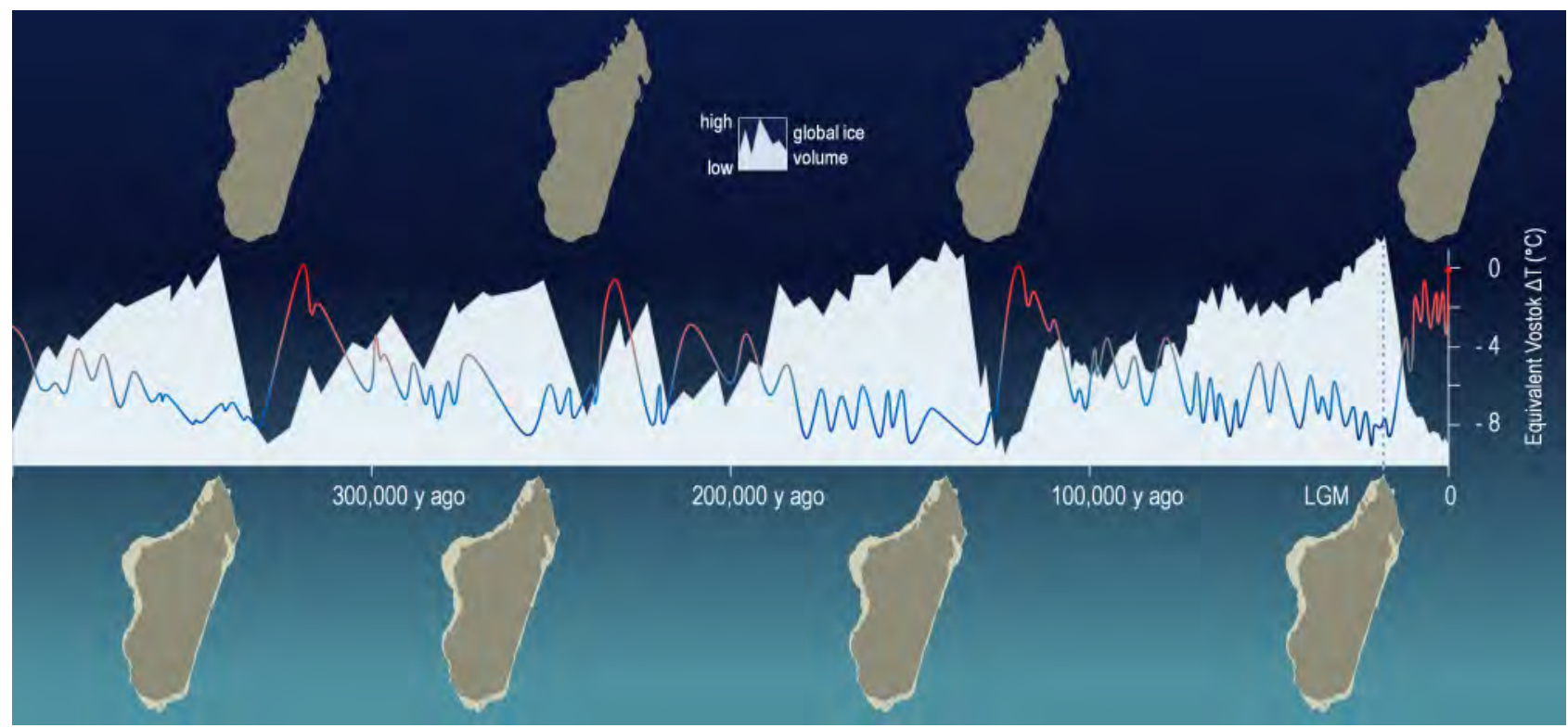

Figure 37. Last glacial/interglacial cycles of the Quaternary with changes in the global ice volume, and temperatures. During cold and dry phases, sea level were some 90 to $130 \mathrm{~m}$ below current level and Madagascar had a larger area including the continental plateau (bottom maps). 
pions is viviparous, with the development of the embryo inside the body of the female. In the genus Grosphus, the gestation can last three to six months (Lourenço and Cloudsley-Thompson 1998, Lourenço and Goodman 2006) and allow a fertile female to settle a new population after passive drifting and landing on new land. The ocean currents along the western continental plateau of the island are variable, and eddies are also known to regularly occur (Heileman et al. 2009). Passive rafting from Madagascar has also been proposed to explain the occurrence of $G$. mayottensis on Mayotte (Lourenço and Goodman 2009). The Indian Ocean South Equatorial Current (SEC) bifurcates into two branches along the east coast of Madagascar; the northward branch feeds into the North Madagascar Current (NMC), which turns at the northern cape of the island and continues westward toward the east coast of Africa over the islands of the Comoros (e.g., Swallow et al. 1988). The ocean currents over the western continental plateau are not as fast and not as straight as the current fed by the SEC and $\mathrm{NMC}$, but the passive rafting along the coast of an ancestral population can be considered because (i) of the absence of a population of these species between these localities distant of more than $1000 \mathrm{~km}$, (ii) the known distribution localities of two sister species G. waeberi sp. n. and G. bistriatus lie near the coast, at distances $<5 \mathrm{~km}$, and (iii) a female Grosphus can protect her offspring in her body during extended periods of times.

The climatic change scenario is best explained in the context of the Quaternary comparatively rapid climate shifts that occurred during the last 2.6 million years. During the cold and dry phases, more of Earth's water was stored as ice, sea level was therefore lower, and forests were receding; during warmer and more humid phases, ice was melting, sea level rose again and forests expanded. For instance, during the last glacial maximum (LGM) some 20,000 years ago, the climate in Madagascar was a lot drier than today, and sea level was at ca. 130m below the current level (e.g., Mercier and Wilmé 2013, Lambeck et al. 2014, Figure 36). The ancestral populations of the nowadays Grosphus ankarafantsika, G. bistratus, G. eliseanneae sp. n. and G. waeberi sp. n. could have been distributed over the continental plateau in ancient times, not necessarily during LGM, but during any cold and dry phase of the paleoclimate oscillations (Figure 37) when sea levels were 90 to $130 \mathrm{~m}$ below current levels. These paleoclimate oscillations had profound effects, not only on the geomorphology of entire landforms, but also on biological evolution and extinction (e.g., Blois et al. 2013). The continental plateau in the region of Cap SainteAndré in the northwest of Madagascar spans over a distance of some $90 \mathrm{~km}$, and could have harbored populations of Grosphus during one or more dry phases of the paleoclimate oscillations. This northwestern portion of the island could have been one of the driest regions, especially the coastal areas where river flow was certainly interrupted during the dry phases of the paleoclimate oscillations (Mercier and Wilmé 2013).

Adaptation to dry biomes is fairly recent amongst scorpions, especially to deserts (e.g., Lourenço et al. 2016a). The families of scorpions represented in Madagascar belong to archaic lineages, but the genus Grosphus has clearly adapted to dry biomes, as shown by the limited number of species currently restricted to humid forests (4 species, i.e., 18\%), amongst which only one, G. voahangyae Lourenço and Wilmé 2015, has a narrow range and seems to be adapted to an extremely peculiar setting (Lourenço and Wilmé 2015b).
Several species of Grosphus are narrow-ranged, as is the case in other groups of scorpions occurring in Madagascar. This can be a bias of the paucity of inventories, especially in the dry forests (Waeber et al. 2015). In the case of a species occurring along or near the coast, the current narrow range could be a recent contraction of a once wider occurrence (scenario 2). During the dry phases of the paleoclimate oscillations, sea level was below the current level; for instance, it was at ca. $130 \mathrm{~m}$ below that of present-day during the last glacial maximum, some 20,000 years ago (Lambeck et al. 2014, Figure 36). Some species of scorpions may have had a wider distribution over the today submerged continental plateau, resulting in a narrow coastal narrow range nowadays. Such historical wider ranges may have existed for G. eliseanneae sp. n. and G. waeberi sp. n., but also for G. bistriatus Kraepelin 1901, G. polskyi Lourenço, Qi and Goodman 2007, G. annulatus Fage 1929, G. magalieae Lourenço 2014, and G. sabineae sp. n.

Grosphus sabineae sp. $\mathrm{n}$. is the 7th species reported from Cap Sainte-Marie. Cap Sainte-Marie is a small reserve with a total area of only 1750 ha, covered with a short dry spiny thicket at an elevation ranging from $110 \mathrm{~m}$ to $180 \mathrm{~m}$ near the lighthouse. The other six species of scorpions occurring in the reserve of Cap Sainte-Marie are: G. feti Lourenço 1996, Neogrosphus griveaudi (Vachon 1969), Pseudouroplectes betschi Lourenço 1995, P. pidgeoni Lourenço and Goodman 1999, Tityobuthus cf. petrae Lourenço 1996, and Opisthacanthus lucienneae Lourenço and Goodman 2006. The reserve is not amongst the key areas for the richness of its vertebrate biodiversity for instance (Goodman and Wilmé 2008). The vegetation is growing with the typical habitus encountered in places with regular and strong winds, and the trees, growing in sand, are extremely short. Cap Sainte-Marie is also known to host at least three species of diplopodes, Zoosphaerium haackeri Wesener 2009, Z. libidinosum (de Saussure and Zehnter 1897) and Riotintobolus anomalus Wesener, Enghoff and Sierwald 2009 (Wesener 2009, Wesener et al. 2009). It is not yet known why and how the setting at Cap Sainte-Marie is favourable for these scorpions and possibly other invertebrates, but this small reserve at the southern tip of Madagascar certainly deserves further studies, as well as full protection.

\section{ACKNOWLEDGEMENTS}

Thanks go to Elise-Anne Leguin for her assistance in the preparation of the photos and plates.

\section{REFERENCES}

Blois, J. L., Zarnetske, P. L., Fitzpatrick, M. C. and Finnegan, S. 2013. Climate change and the past, present, and future of biotic interactions. Science 341: 499-504. (doi:10.1126/science.1237184)

Cornet, A. 1974. Essai de Cartographie Bioclimatique à Madagascar. Notice Explicative $N^{\circ}$ 55. ORSTOM, Paris.

Fage, L. 1929. Les Scorpions de Madagascar. Faune des Colonies françaises 3, pp 637-694. Société d'Éditions Géographiques Maritimes Coloniales, Paris.

Goodman, S. M. \& Wilmé, L. (eds.) 2008. Les Forêts Sèches de Madagascar. Malagasy Nature 1: 1-193.

Hjelle, J. T. 1990. Anatomy and morphology. In: The Biology of Scorpions. G. A. Polis (ed.), pp 9-63. Stanford University Press, Stanford.

Kraepelin, K. 1900. Üeber einige neue Gliederspinnen. Abhandlungen aus dem Gebiete der Naturwissenschaften 16: 3-17.

Kraepelin, K. 1901. Catalogue des scorpions des collections du Muséum d'histoire naturelle de Paris. Bulletin du Muséum national d'Histoire naturelle, Paris 7: 263-265. 
Lambeck, K., Rouby, H., Purcell, A., Sun, Y. and Sambridge, M. 2014. Sea level and global ice volumes from the Last Glacial Maximum to the Holocene. Proceedings of the National Academy of Sciences of the United States of America 111, 43: 15296-15303. (doi:10.1073/pnas.1411762111)

Lourenço, W. R. 1996. Scorpions (Chelicerata, Scorpiones). Faune de Madagascar. Muséum national d'Histoire naturelle, Paris.

Lourenço, W. R. 2001. Another new species of Grosphus Simon (Scorpiones, Buthidae) for Madagascar. Revue Suisse de Zoologie 108, 3: 455-461.

Lourenço, W. R. 2003. New taxonomic considerations on some species of the genus Grosphus Simon, with description of a new species (Scorpiones, Buthidae). Revue Suisse de Zoologie 110, 1: 141-154.

Lourenço, W. R. 2014. The genus Grosphus Simon, 1880 from South-western Madagascar, with the description of a new species (Scorpiones, Buthidae). Zoosystema 36, 3: 631-645. (doi:10.5252/z2014n3a5)

Lourenço, W. R. and Cloudsley-Thompson, J. L. 1998. Notes on the ecology and postembryonic development of Grosphus flavopiceus Kraepelin, 1901 (Scorpiones, Buthidae) from the Ankarana mountain range in the North of Madagascar. Biogeographica 74, 4: 183-187.

Lourenço, W. R. and Goodman, S. M. 2006. Notes on the postembryonic development and ecology of Grosphus hirtus Kraepelin, 1901 (Scorpiones, Buthidae) from the Parc National d'Ankarafantsika, northwest Madagascar. Zoologischer Anzeiger 244, 3-4: 181-185. (doi:10.1016/j.jcz.2005.09.001)

Lourenço, W. R. and Goodman, S. M. 2009. Scorpions from the Comoros Archipelago: Description of a new species of Grosphus Simon (Scorpiones, Buthidae) from Mayotte (Maore). Boletín Sociedad Entomológica Aragonesa 44 35-38.

Lourenço, W. R. and Wilmé, L. 2015a. Scorpions collected in the Makay Mountain range, Madagascar (Scorpiones: Hormuridae, Buthidae) and description of a new species. Revista Ibérica de Aracnología 26: 55-61.

Lourenço, W. R. and Wilmé, L. 2015b. Species of Grosphus Simon, 1880, associated to the group madagascariensis/hirtus (Scorpiones: Buthidae); description of a peculiar new species from the humid eastern forests of Madagascar. Entomologische Mitteilungen aus dem Zoologischen Museum Hamburg 17, 194: 207-223.

Lourenço, W. R., Qi, J.-X. and Goodman, S. M. 2007. Scorpions of southwest Madagascar. A new species of Grosphus Simon, 1880 (Scorpiones, Buthidae). Boletín de la Sociedad Entomológica Aragonesa 40: 171-177.

Lourenço, W. R., Soarimalala, V. and Goodman, S. M. 2009. The species of Grosphus Simon (Scorpiones, Buthidae) distributed in the northern and eastern regions of Madagascar with the description of a new species. Malagasy Nature 2: 144-153.

Lourenço, W. R., Wilmé, L. and Waeber, P. O. 2015c. More about the geographical distribution of the Malagasy genus Neogrosphus Lourenço, 1995 (Scorpiones: Buthidae) and description of a vicariant new species. Comptes Rendus Biologies 338, 11: 768-776. (doi:10.1016/j.crvi.2015.08.001)

Lourenço, W. R., Waeber, P. O. and Wilmé, L. 2016a. The geographical pattern of distribution of the genus Tityobuthus Pocock, 1890, a typical Ananterinae element endemic to Madagascar (Scorpiones: Buthidae). Comptes Rendus Biologies. (doi:10.1016/j.crvi.2016.06.003)

Lourenço, W. R., Wilmé, L. and Waeber, P. O. 2016b. More about the geographical pattern of distribution of the genus Pseudouroplectes Lourenço, 1995 (Scorpiones: Buthidae) from Madagascar. Comptes Rendus Biologies 339, 1 : 37-43. (doi:10.1016j.crvi.2015.11.001)

Mercier, J.-L. and Wilmé, L. 2013. The Eco-Geo-Clim model: explaining Madagascar's endemism. Madagascar Conservation \& Development 8, 2: 63-68. (doi:10.4314/mcd.v8i2.3)

Moat, J. and Smith, P. (eds.) 2007. Atlas of the Vegetation of Madagascar. Kew Publishing, Royal Botanic Gardens, Kew.

Simpson, G. G. 1940. Mammals and land bridges. Journal of the Washington Academy of Sciences 30: 137-163.

Stahnke, H. L. 1970. Scorpion nomenclature and mensuration. Entomological News 81: 297-316

Stankiewicz, J., Thiart, C., Masters, J. C. and de Wit, M. J. 2006. Did lemurs have sweepstake tickets? An exploration of Simpson's model for the colonization of Madagascar by mammals. Journal of Biogeography 33, 2: 221-235. (doi:10.1111/j.1365-2699.2005.01381.x)
Strand, E. 1908. Arachniden aus Madagaskar, gesammelt von Herrn Walter Kaudern. Zoologische Jahrbücher, Abtheilung für Systematik 26: 453-488.

Vachon, M. 1952. Études sur les Scorpions. Institut Pasteur d'Algérie, Alger

Vachon, M. 1963. De l'utilité, en systématique, d'une nomenclature des dents des chélicères chez les Scorpions. Bulletin du Muséum national d'Histoire naturelle, Paris 2e sér., 35, 2: 161-166.

Vachon, M. 1974. Étude des caractères utilisés pour classer les familles et les genres de Scorpions (Arachnides). 1. La trichobothriotaxie en arachnologie. Sigles trichobothriaux et types de trichobothriotaxie chez les Scorpions. Bulletin du Muséum national d'Histoire naturelle, Paris, 3e sér., N. 140, Zool. 104: 857-958.

Vachon, M. 1975. Sur I'utilisation de la trichobothriotaxie du bras des pédipalpes des Scorpions (Arachnides) dans le classement des genres de la famille des Buthidae Simon. Comptes Rendus des Séances de l'Académie des Sciences 281, D: 1597-1599.

Waeber, P. O., Wilmé, L., Ramamonjisoa, B., Garcia, C., Rakotomalala, D., Rabemananjara, Z. H., Kull, C., Ganzhorn, J. U. and Sorg, J.-P. 2015. Dry forests in Madagascar, neglected and under pressure. International Forestry Review 17, S2: 127-148. (doi:10.1505/146554815815834822)

Wesener, T. 2009. Unexplored richness: discovery of 31 new species of Giant PillMillipedes endemic to Madagascar, with a special emphasis on microendemism (Diplopoda, Sphaerotheriida). Zootaxa 2097: 1-134.

Wesener, T., Enghoff, H. and Sierwald, P. 2009. Review of the Spirobolida on Madagascar, with descriptions of twelve new genera, including three "fire millipede" ones (Diplopoda). ZooKeys 19: 1-128. (doi:10.3897/zookeys.19.221)

Wilmé, L., Goodman, S. M. and Ganzhorn, J. U. 2006. Biogeographic evolution of Madagascar's micro-endemic biota. Science 312: 1063-1065. (doi:10.1126/science.1122806)

Wilmé, L., Ravokatra, M., Dolch, R., Schuurman, D., Mathieu, E., Schuetz, H. and Waeber, P. O. 2012. Toponyms for centers of endemism. Madagascar Conservation \& Development 7. 1: 30-40. (doi:10.4314/ mcd.v7i1.6) 